\title{
System Dynamics Analysis on the Coordinated Development of Higher Education in Beijing,Tianjin and Hebei
}

\author{
Yue Qiu, Yiru Su, Chuansheng Wang and Haiqing Cao \\ School of Information, Capital University of Economics and Business, Beijing, China
}

\begin{abstract}
Beijing, Tianjin and Hebei's (BTH) higher education coordinated development is a significant component of the BTH's coordinated development. There is seriously existed the shortage of teacher resources; and there is low cooperative index between higher education and industrial structure; the quality and scale of high educational talents also out-of-balance. Applying the core of SD theory, a basic analytical framework of BJH's higher education accord development should be establish. According to a rigorous causality to consider it's influence factors and constraints, to find the source of development. Also the correct countermeasure should be implement on investment of education research funding, improvement of the teachers resources, new enrollments of universities, regional production and research degree to enhance the cooperation and development of BTH's higher education.
\end{abstract}

Keywords-system dynamics; coordinated development; education resource

That is a major national strategy to achieve the coordinated development of Beijing-Tianjin- Hebei. The coordinated development of higher education of Beijing-Tianjin-Hebei plays an important role in talent support and intellectual support. The coordinated development of higher education in Beijing-Tianjin-Hebei has the strategic significance as an important driving force to promote social innovation and social development. The integration of higher education in BeijingTianjin-Hebei is to break the obstacles of long-term development and circulation of higher education. Then play the comparative advantage of education in Beijing, Tianjin and Hebei to mutual benefit and win-win, complementary advantages. And allocate funds to human resources reasonably.

So many scholars have studied the integration of BeijingTianjin-Hebei from different fields since the coordinated development of Beijing-Tianjin- Hebei have been proposed. They study it from different angles, and use the different disciplines of professional knowledge and methods. But on the whole, these studies are more fragmented, most of them qualitative analysis, quantitative analysis is just a little, and most of them are studying the relationship between the static situation.

In view of the integration of Beijing-Tianjin-Hebei higher education is a typical complex system because of the impact of multiple factors. However, system dynamics can effectively combine the quantitative analysis and qualitative analysis with the computer simulation technology and based on the feedback control theory. It could depth study of complex information system feedback behavior, to find and study the relevant factors in the system from the system as a whole.

The current situation of the medical development in Beijing-Tianjin-Hebei region.

\section{The Status QuO OF THE BeIJING-TIANJIN-ShanghaI HighER EDUCATION COORDINATED DEVELOPMENT}

The analysis of the health situation of Beijing-TianjinHebei region find that the health development of the BeijingTianjin-Hebei region exist the following problems.

For the status quo of the distribution of higher education resources in Beijing, Tianjin and Hebei, it has an absolute advantage from a national perspective. But the resources of higher education show the characteristics of uneven distribution. Beijing is in the advantages of higher education resources, while Hebei is at a disadvantage; the overall disparity of the structure of higher teachers in BTH is also relatively large. Teachers with senior titles in Beijing are far higher than the national average, while the number of teachers with primary titles and no titles is lower than the national level. On the contrary, the number of teachers with junior titles and non-title in Hebei Province is higher than the national average, and the teachers in Tianjin are correspondingly lower than the national average. That is, the teachers in Beijing are generally at a high level, while Tianjin and Hebei are at a low level. The low compatibility of the BTH higher education coordinated development and regional industry, which will lead to a lower conversion rate of scientific and technological achievements. According to the statistics of BTH high school R \& D, Beijing has the most personnel and funds, followed by Tianjin and Hebei. In short, the development of higher education gap is obvious of BTH. Beijing's higher education level is much higher than Tianjin and Hebei whether from the allocation of funds, teachers or scientific research output and scientific and technological achievements in terms of conversion. It not only increased the possibility of Beijing's non-capital function, to bring pressure on Beijing, and also not conducive to the overall regional coordinated development. In addition, the higher education is the soft environment of regional development, the high-quality higher education resources are conducive to attract talent, cultivate talent, and promote development of the local economic, cultural, social. So this paper analyzes the BTH higher education collaborative development factors and constraints, then build the basic framework. 


\section{CONSTRUCTION OF A MODEL FRAMEWORK FOR SYSTEM DYNAMICS OF EDUCATIONAL}

The BTH Higher Education Collaborative Development System is a complex system, that involving many factors such as economy and policy. These factors are complicated and varied, To establish a system dynamics model for the harmonious development of higher education in BeijingTianjin-Hebei region. Consider the specific situation of colleges and universities, but also consider the social and economic factors related to the role of cross-feedback.

First of all, BTH higher education collaborative development system is divided into three regional higher education development subsystem, the three subsystems internal structure of the same, but between the three and each other. Among them, an area as an example to establish a regional model for the development of higher education model.

\section{A. System Boundary Determination and Basic Assumptions}

- Determination of system boundaries

- From the System dynamics, the internal factors determine the behavior of the system, external factors often do not play a decisive role, so choose a reasonable system boundary is related to the success of the model key. From the structural point of view, higher education collaborative development system mainly includes teacher subsystem, funding subsystem, regional production and research with the subsystem.

\section{- Model basic assumptions}

$\mathrm{H} 1$ : Assuming that the enrollment rate remains the same, the impact of the policy is not expanding.

H2: Teacher positions and discipline literacy remains the same, regardless of the quality of teachers to train students.

H3: Do not consider the quality of their own students, do not consider the quality of students on the quality of the impact of graduates

H4: 2005 data for the initial value of the simulation, step length of 1 year, time period: 2005 - 2010

- Establishment of regional higher education development causal loop model

- $\quad$ Teacher Subsystem

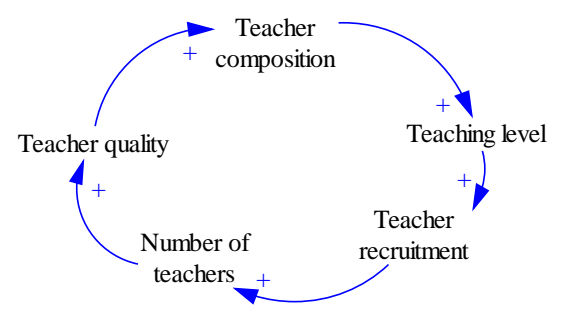

It can be seen from the figure is a teacher subsystem of the causal diagram, is a positive feedback loop. The reality is that the higher the level of teachers, the higher the level of teaching, the higher the recruitment requirements of teachers, the higher the number of teachers, the greater the number of teachers, the overall level of teachers will decline. This requires continuous improvement of the quality of teachers. To play the role of the government's macro-control, to develop relevant policies to encourage teachers in Beijing and Tianjin to Hebei institutions, Hebei University for the backbone of the Beijing area teachers to help exchange and improve the overall quality of teachers in Hebei level, so as to improve the teaching level and scientific research ability.

- College funding sub-system
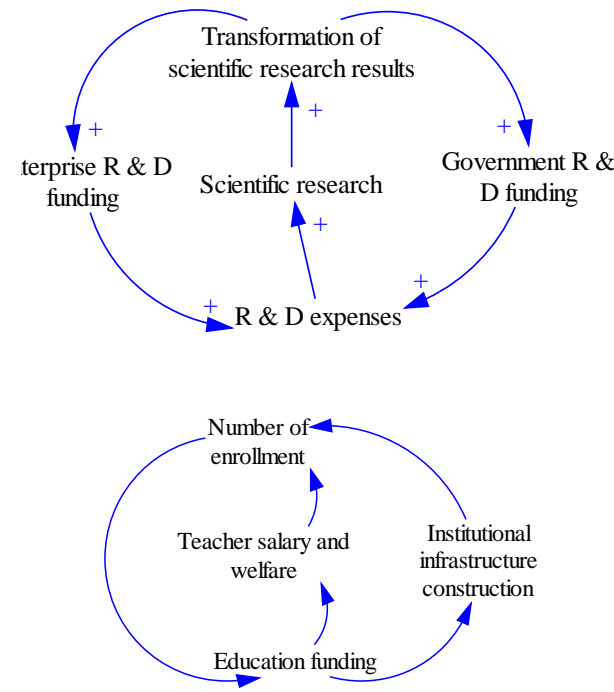

The above figure shows the causal circuit of the sub-system of the institutions of higher learning, both of which are positive feedback loops. Reflect the situation is: R \& D funds increased, the school received research funding increased, the amount of scientific research will increase the value of scientific research to increase the value of the increase in revenue, government and business investment in $\mathrm{R} \& \mathrm{D}$ funds increased. It is concluded that it is necessary to increase the investment of R \& D funds in Hebei area, support the scientific research activities of universities and promote the output of scientific research achievements, so as to improve the commercialization of the results and promote the development of regional GDP.

In addition, the increase in education funds, staff salaries and benefits increased, while the level of basic hardware and software institutions to improve the number of enrollment increased, with the increase in the number of enrollment, education funding increased. Therefore, the government should increase investment in education in Hebei and Tianjin, increase the salary and benefits of teachers, improve the teaching level, strengthen the construction of hardware and software facilities, improve the teaching environment, improve the quality of students and attract students. 


\section{Production and research cooperation subsystem}

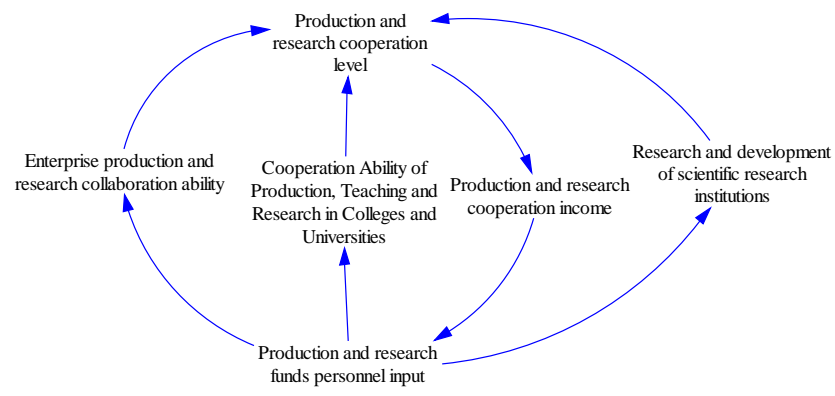

The picture shows the regional production and research cooperation subsystem causal circuit diagram, for the positive feedback loop, production and research personnel to increase investment, business. Universities, scientific research institutions of production and research cooperation will improve the ability to innovate, along with the level of cooperation in research and research cooperation, production and research cooperation income increased, production and research platform for the increase in capital personnel. Therefore, it is necessary to improve the ability of cooperating with the three schools of industry and technology, through the government policy control, increase the support of production and research, improve the output of scientific research achievements, improve the commercialization of knowledge products, improve the new product income, increase the regional GDP, Large institutions of higher learning and development of the Association, the development of regional economy and adapt to the characteristics of the subject, to provide students with more suitable internship positions, improve the quality of graduates, improve the employment environment, improve the employment rate of graduates.

\section{B. Analysis of the Factors Influencing the Coordinated Development of Regional Higher Education \\ External factors}

The government plays a role in macroeconomic regulation and control, which provides institutional guarantee and funding guarantee for the development of higher education. In addition, the Ministry of Education through the development of disciplines professional development plan, professional development requirements to guide, at the same time play the autonomy of colleges and universities; Second, through the policy to guide the stimulation of the teachers in Beijing and Tianjin region Transfer of counterparts and improve the level of teachers in Hebei colleges and universities. Finally, the government needs to actively encourage the participation of social forces, and give full play to the autonomy of colleges and universities to form an effective self-regulatory mechanism.

The market, refers to the local enterprises and institutions, local enterprises and institutions, should pay attention to the practical training of students, increase the number of interns, interns "one with" training, strengthen the joint training of school and enterprise. At the same time to increase cooperation with institutions of higher learning to promote the combination of production and research, improve the industrialization of scientific research income, increase investment in production and research platform.

\section{Internal factors}

The level of teachers is the basis of the teaching level of institutions of higher learning.

The hardware and software facilities of higher education institutions, is an important factor affecting the development of local higher education

\section{Analysis on the Flowchart of Regional Higher Education Flow}

- The variables involved in the model

TABLE I. THE VARIABLES INVOLVED IN THE MODEL

\begin{tabular}{|c|c|c|c|}
\hline Number & Variable & Unit & Variable type \\
\hline 1 & $G D P$ & Million & $\mathrm{L}$ \\
\hline 2 & GDP growth & Million & $\mathrm{R}$ \\
\hline 3 & GDP growth rate & Million & $\mathrm{C}$ \\
\hline 4 & Government spending on education & Million & A \\
\hline 5 & Government founding & -- & $\mathrm{C}$ \\
\hline 6 & The propoetion of staff salaries & -- & $\mathrm{C}$ \\
\hline 7 & Average salary of faculty and staff & -- & A \\
\hline 8 & Attractiveness of faculty & -- & A \\
\hline 9 & Number of teachers in Hebei colleges & Person & $\mathrm{C}$ \\
\hline 10 & Numebi of faculty and stuff & Person & A \\
\hline 11 & Government support factor & -- & $\mathrm{C}$ \\
\hline 12 & Teacher-student ratio & -- & A \\
\hline 13 & Teacher-student ratio impact factor & -- & A \\
\hline 14 & Enrollment rate & -- & A \\
\hline 15 & Creditmutual recognition factor & -- & $\mathrm{C}$ \\
\hline 16 & Number of admissions & Person & $\mathrm{R}$ \\
\hline 17 & Numbei of students in school & Person & $\mathrm{L}$ \\
\hline 18 & Numbei of gradustes & Person & A \\
\hline 19 & Employment environment & -- & A \\
\hline 20 & Papers and books & item & $\mathrm{L}$ \\
\hline 21 & Numbei of graduates employed & Person & $\mathrm{L}$ \\
\hline 22 & Gradustion rate & -- & \\
\hline 23 & Graduates'employment growth & person/year & $\mathrm{R}$ \\
\hline 24 & Graduate employment rate & -- & A \\
\hline 25 & University $R \& D$ expenditure ratio & -- & $\mathrm{C}$ \\
\hline 26 & Expenditure on $R \& D$ in Colleges & million year & A \\
\hline 27 & Papers and writings for several years & item/year & $\mathrm{R}$ \\
\hline 28 & University $R \& D$ personnel input & person/year & A \\
\hline 29 & Patent growth & item/year & $\mathrm{R}$ \\
\hline 30 & Number of patent applications & item/year & $\mathrm{L}$ \\
\hline 31 & Business cooperation results & item & A \\
\hline 32 & Average value of university achivement & -- & $\mathrm{C}$ \\
\hline 33 & 1 rate of scientific and technological aci & -- & A \\
\hline 34 & Annual income & million & $\mathrm{L}$ \\
\hline 35 & ombination of production and research & -- & $\mathrm{R}$ \\
\hline 36 & duction and research cooperation inco & million & $\mathrm{L}$ \\
\hline 37 & Number of business results & item & A \\
\hline 38 & Enterprise $R \& D$ personnel input & person/year & $\mathrm{C}$ \\
\hline 39 & Corporate $R \& D$ expenses & million & A \\
\hline 40 & sccounted for the proportion of the ma & -- & $\mathrm{C}$ \\
\hline 41 & Business cooperation will & -- & A \\
\hline
\end{tabular}

Note: $\mathrm{L}$ is the state variable; $\mathrm{R}$ is the rate variable; $\mathrm{A}$ is the auxiliary variable; $\mathrm{C}$ is the constant.

- Regional Higher Education Development Flow Chart 


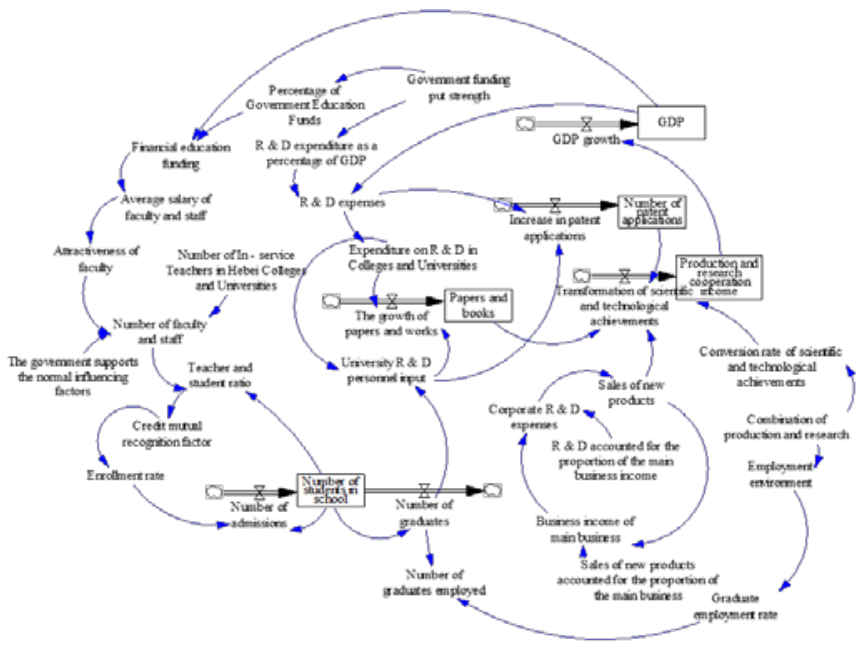

The figure shows the development of a higher education in the region of the stock flow chart, according to the establishment of the above Beijing, Tianjin, Hebei three subsystems.

On the basis of considering the computability and reality of the data, the causal diagram is simplified and summarized. According to the national policy and the relevant factors influencing the development of higher education in the region, the flow of the regional higher education development flow chart is obtained. The relationship between the initial data and the variables in this study is based on the Beijing Statistical Yearbook, the Hebei Statistical Yearbook, the Tianjin Statistical Yearbook and the China Statistical Database on Economic and Social Development, as well as visits to relevant educational sector experts and scholars, List the main formulas involved in the model. Number of employed persons = INTEG (Graduate employment growth, 183213);

Papers and writings = INTEG (papers and writings growth, 26667);

Financial education expenditure $=G D P *$ government financial education investment intensity;

The number of faculty and staff in colleges and universities $=$ the number of government support policies * the number of in - service teachers in Hebei colleges and universities * the attraction of faculty and staff in colleges and universities;

$R \& D$ Expenditure $=G D P * R \& D$ Fund Internal expenditure Proportion of GDP $+R \& D$ expenditure;

Patent sale proceeds $=$ patent sale rate $*$ patent price $*$ patent application amount;

Government support policy impact factor $=1$;

Credit factor $=1$;

Government funding strength $=1$;

Production and research degree $=1$;

\section{Model Putput}

The system dynamics model is used to study the factors that affect the level of higher education in the region. Therefore, the number of graduates in higher education institutions is chosen as the main output value of the model, which reflects the direct output of regional higher education. In order to test the correctness of the system dynamics model Sex, select the production and research cooperation income for the second output, to indirectly reflect the level of regional higher education development and the overall level of collaborative development.

First of all, the effectiveness of the model test, mainly in Hebei Province, the number of institutions of higher learning enrollment, the number of graduates, the number of teachers, the number of scientific research, production and research collaborative profit simulation. Secondly, the model scope adaptability, the establishment of the model is based on a large number of related literature and the Beijing-Tianjin-Hebei synergies related to the policy of reading, the model itself includes the purpose of building the model of almost all the main variables and feedback structure, some unnecessary exogenous Variables are not included in the model, and it is meaningful to verify that each model is appropriate. Finally, the model consistency test is used to test the validity of the system model of Beijing - Tianjin - Hebei educational development through the simulation of the system simulation between 2005 and 2005 and the actual historical data.

\section{PARAMETER DETERMINATION}

In the process of running the model, except simulate about the three higher education development process. But also to inspect some part of the model operating parameters for the simulation results. So this paper is mainly from the teacher, enrollment, funding, production and research four aspects of the relevant parameters.

\section{A. Change the Meaning of Parameters}

First, change the government to support the impact factors. Find the impact on teachers. The government of BeijingTianjin-Hebei higher education coordinated development can take the relevant strategies to take "one to one" policy. The outstanding teachers of Beijing's Universities support Hebei Tianjin institutions, Change its teacher structure. Improve the teachers and students in Hebei and Tianjin, and optimize the teachers' resources in both places.

Second, change the factors of mutual recognition of credit factors. Beijing and Tianjin universities can take credit recognition policy, so for the field and the local college entrance examination fresh places, are likely to increase the number of admissions in Hebei, Tianjin, Beijing University to ease the number of applicants, the number of students in the school pressure.

Third, change the intensity of government investment. Hebei, Tianjin government funding for education and R \& D funding is far from enough compared with Beijing. It not only affected the regional level of teachers, university infrastructure, but also affected institutions of higher learning Of the scientific research results, is not conducive to improving the employment rate of students in colleges and universities, is not conducive to the local real estate research and cooperation income area GDP development. Therefore, it is necessary to increase the 
government funding of Tianjin and Hebei, to coordinate the allocation of resources of regional institutions of higher learning, and to attract outstanding teachers to improve the level of $\mathrm{R} \& \mathrm{D}$ of local universities and enterprises, so as to improve the level of regional teaching and technological development.

Fourth, improve the degree of integration of production and research. That is, for regional industry and technology needs the establishment of regional characteristics of professional, and regional industrial counterpart research and development. At present, there are colleges and universities research direction, scientific research and business needs are not linked to the phenomenon, which will not only reduce the income of scientific and technological achievements in colleges and universities, but also is not conducive to regional industries to improve the level of technology and product sales, but also indirectly affect local GDP growth. This requires the BeijingTianjin-Hebei three places development of industry and adapt to the characteristics of disciplines especially Tianjin, Hebei need according to the local industry types and characteristics, such as Tianjin's port industry and Hebei manufacturing industry. And improve the level of regional production and research, the employment rate of students in colleges and universities, the promotion of regional GDP development, and improve the overall income of industry, academia and research and GDP growth in Beijing, Tianjin and Hebei provinces.

\section{B. Change the System Impact Factor}

To change the investment intensity of Beijing sub-system, the factors of mutual recognition of credit, the influence factors of government support, the degree of integration of production and research, and the simulation results through model. Output variables were seen in the number of students, graduates employment, the number of papers and writings, production and research cooperation income.

Through the model simulation simulation output results, to determine the changes in the number of indicators in the school, the number of graduates, the number of papers and writings, production and research cooperation benefits. According to the magnitude of the change, to establish the weight of Beijing and Tianjin to adjust the three factors. Assuming that the weight of the mutual recognition effect of the credit is a, the weight of the government support factor is b, the weight of the government investment is $c$, and the weight of the degree of integration is $d$, $\mathrm{a}+\mathrm{b}+\mathrm{c}+\mathrm{d}=1$.

The three sub-subsystems through the impact of four influencing factors connected to change the three related impact parameters, as shown in Table 2:

TABLE II. THE VALUE OF BTH EDUCATIONAL COOPRATIVE MODEL

\begin{tabular}{cccc}
\hline & Bei jing & Tianjin & Hebei \\
Credit mutual recognition factor & $1-2 \mathrm{a}$ & $1+\mathrm{a}$ & $1+\mathrm{a}$ \\
Government support policy impact factor & $1-2 \mathrm{~b}$ & $1+\mathrm{b}$ & $1+\mathrm{b}$ \\
The intensity of government funding & $1-2 \mathrm{c}$ & $1+\mathrm{c}$ & $1+\mathrm{c}$ \\
Combination of production and research & $1-2 \mathrm{~d}$ & $1+\mathrm{d}$ & $1+\mathrm{d}$ \\
\hline
\end{tabular}

Through the above changes in the value of the parameters to simulate the 2010 - 2015 year five years of data, compared with the actual historical data, compared to change the parameters before and after the Beijing-Tianjin-Hebei three provinces to change the output variables and Beijing-TianjinHebei three overall output variables The change. Beijing, Tianjin, Hebei, the three places in the school population, graduate employment population, industry and academia collaborative income changes, so as to solve the large number of students in Beijing, the population pressure, improve the level of education in Tianjin, Hebei and production and research cooperation level, Promote Tianjin, Hebei economic development.

\section{SUMMARY}

The authors would express sincere appreciation to the support from the Beijing Municipal Education Commission Foundation of China (Project no. KM 201410038001) .

System dynamics modeling is an important method to study the complex system in the field of social economy. Based on the co-development of Beijing-Tianjin-Hebei higher education, this paper analyzes the relationship between the various factors within the system, Theoretical Model of Synergetic Development of Higher Education in Beijing, Tianjin and Hebei. Based on the data of "Beijing Statistical Yearbook", "Hebei Statistical Yearbook", "Tianjin Statistical Yearbook" and "China Economic and Social Development Statistics Database", we will study the development of higher education in Beijing and Tianjin in the next 20 years Conduct empirical research.

\section{ACKNOWLEDGMENT}

The authors would express sincere appreciation to the support from the Beijing Municipal Education Commission Foundation of China (Project no. KM 201410038001).

\section{REFERENCES}

[1] Wang Qi fan System dynamics [M]. Tsinghua University Press, 1988: 1 4..Zhangyu, Zhang Lulu, Ma Yuqin. "rural medical human behavior choice" modeling design [J]. China's rural health service management. 2009, 29 (11) : 812-814

[2] Zhong Yong guang, Jia Xiaojing, Qian Ying. System dynamics [M]. Science Press, 2013: 1 276.

[3] Wang Yingluo. System Engineering [M]. Higher Education Press, February 2007: $128 \sim 147$.

[4] [4] Xi Jinping. Xi Jinping on the development of Beijing and Tianjin to mention 7 requirements: to break their own one-third of the land to think. Xinhua News Agency. Http: //finance.ifeng.com/a/20140227/ 11765215_0.shtml.

[5] [5] Wu Mei. Construction of Beijing-Tianjin-Hebei higher education resources sharing mechanism [J]. Tianjin Economic, 2010: $14 \sim 18$.

[6] [3] Gao Bing. Spatial layout and regional development of higher education in Beijing, Tianjin and Hebei: relations, characteristics and conception $[\mathrm{J}]$.

[7] Journal of the University, 2013: $106 \sim 111$.

[8] [7] to build "Yangtze River Delta comprehensive education reform pilot area" task group to promote the Yangtze River Delta comprehensive education reform area

[9] Domain education linkage development [J]. Educational Development Research, 2012: $27 \sim 45$. 
[10] [8] Hu Xiaoying.Study on the Optimization of Higher Education Structure in Hebei Province from the Perspective of the Main Functional Area of Beijing, Tianjin and Hebei [D]. Hebei: Hebei University of Science and Technology, 2011: $26 \sim 44$.

[11] Fan Hexiang. Relief function of the capital Beijing study [J]. Journal of the front line, 2015 (11) 